\title{
Nuria Morère Molinero y Salvador Perelló-Oliver (2013): Turismo Cultural: Patrimonio, museos y empleabilidad. Madrid: Fundación de la Escuela de Organización Industrial, 134 p. ISBN: 978-84-15061-37-3
}

Definir al turismo cultural parece aún hoy, a esta altura del avance de su estudio, una tarea compleja, un permanente proceso en construcción, una suerte de work in progress, donde no existe una unanimidad de criterios a la hora de unificar categorías de análisis, en la medida en que su definición se puede abordar desde distintas perspectivas.

La relación entre el turismo y la cultura, de todos modos, no es una novedad. La cultura ha sido siempre un elemento traccionador del turismo desde la Antigüedad, haciéndose ésto más visible desde la época del "Grand Tour". La cultura es y será uno de los grandes atractivos que le dan sentido al turismo, algo ya señalado hace 60 años por la Comisión Europea de Turismo al destacar que los paisajes, monumentos, ciudades y costumbres, constituían un capital turístico. De este potencial se ha ido tomando conciencia progresivamente, al punto de convertirse en un importante protagonista de la recuperación urbanística, arquitectónica y funcional de muchos lugares. De hecho, la gestión y conservación del patrimonio histórico y cultural tiene en nuestras sociedades una enorme relevancia estratégica y crecientes consecuencias económicas.

Entender esta incidencia, su impacto en la empleabilidad y la necesidad de nuevos perfiles en la formación profesional para responder a los crecientes desafíos que plantea el turismo cultural es el eje de la investigación de Nuria Morère Molinero y Salvador Perelló Oliver, profesores de la Universidad Rey Juan Carlos, de Madrid, que publica la Escuela de Organización Industrial. Se trata de un trabajo relevante, que supera los enfoques descriptivos para abordar planteos más profundos, ofrecer diagnósticos empíricos, explorar nuevas líneas de trabajo y hacer propuestas de mejora, en sintonía con las nuevas demandas de la sociedad.

El objetivo del estudio es desarrollar el concepto de turismo cultural -como una actividad diferenciada del turismo de masas prototípico de los años 60 del siglo pasado- y su evolución como categoría estrechamente ligada al patrimonio, así como caracterizar sus modelos y políticas de gestión y sus redes profesionales, con especial hincapié en los museos como atractivo turístico patrimonial.

Vale la pena destacar aquí la relación que establecen los autores entre los museos y los sitios Patrimonio de la Humanidad declarados por la UNESCO. Desde los años 80, la valoración de estos bienes, además de un factor de protección y reconocimiento, se ha considerado como un indicador de prestigio patrimonial, de imagen y de gestión turística de calidad. Para los autores, deben considerarse como complemento de los museos en términos de atracción turística y de unión entre el sector de la cultura y el turismo.

Más allá del análisis que se hace del papel de los museos como uno de los sustentos del turismo cultural, el trabajo se adentra en la configuración del turismo cultural como organización en redes y en las estrategias y acciones de cooperación que se establecen y dan cuerpo a esta categoría turística y se reflejan en un contexto de contactos, colaboraciones, convenios y hechos concretos.

Una de las riquezas de la investigación llevada a cabo por los profesores Morère y Perelló radica en la cantidad y calidad de testimonios recogidos por distintos actores de los ámbitos públicos, privados, del turismo y de la cultura, quienes han proporcionado información precisa sobre los niveles de colaboración, gestión y organización, muy valiosos para el análisis.

También son reveladoras las definiciones relativas a la empleabilidad en el sector. Como se señala en el capítulo correspondiente, de forma unánime, los expertos coinciden en indicar que el trabajador de turismo cultural tiene un perfil multidisciplinar, que proviene tanto del turismo como de disciplinas más humanísticas como historia, historia del arte, geografía, arqueología o, incluso, de aquellas carreras más relacionadas con la comunicación como periodismo, publicidad y relaciones públicas.

De la riqueza de testimonios recogidos se desprende que esta multidisciplinariedad no siempre es vista de manera positiva, pues los profesionales del turismo se quejan cuando los empleadores buscan personal con perfiles especializados. De esta manera, los entrevistados coinciden en la participación de muchas especialidades en el campo del turismo cultural y menos en la especialización de profesionales o especialistas en turismo. Como señalan los autores, se trata básicamente de una multidisciplinariedad cultural a la que, quizás, puedan acceder otras áreas.

Otro dato interesante que arroja el trabajo es el más reciente cambio de visión en el área de la administración pública en su política de contrataciones, pues si durante años el empleo en turismo cultural que llegaba a las administraciones se delegaba a empresas subcontratadas, se tercerizaba, cada vez más se constata que estas competencias las deben asumir, en la medida de lo posible, los mismos trabajadores públicos, lo que abre nuevos horizontes en materia de capacitación y de salida laboral.

En relación a la formación y perfiles, se sostiene que una de las carencias más señaladas a la hora de 
valorar la empleabilidad y las competencias específicas de los trabajadores de turismo cultural, es la falta de una formación específica en esta tipología turística. Numerosos testimonios recogidos en el área de museos, en agencias de viajes y otras áreas relacionadas, así lo demuestran. La debilidad que más se destaca para el turismo cultural es la poca especialización de la carrera de turismo. Se trata de una cuestión que, de algún modo, se cubre a través de la paulatina experiencia profesional que va adquiriendo la persona, o a través de formación complementaria, como se refleja en el caso de las agencias de viajes. Según se desprende de los testimonios, los estudios en turismo se consideran, de hecho, demasiado enfocados hacia la empresa. Esto se entiende en la medida en que la especialidad exige conocimientos y matices que no se imparten en un solo espacio académico y que, de hecho, según revela la experiencia española al menos, no se están enseñando en Turismo. Pero, en cambio, otros expertos privilegian el estudio de la gestión a otros conocimientos humanísticos.

La investigación también revela que no existe una acotación clara al turismo cultural en los planes de estudio a nivel de grado, si bien estas carencias están siendo compensadas en España por los posgrados y másteres en la especialidad. Es un dato importante si se piensa que el número de viajeros culturales ha venido creciendo en los últimos años. El trabajo que estamos analizando destaca que, en países como España, del 2005 al 2011 -con la excepción del 2009ha aumentado un 90 por ciento, mientras que el total de los turistas ha crecido un 1,4 por ciento.

Estos dilemas no hacen sino reforzar la idea del turismo cultural como un concepto en permanente construcción donde se comprueba que sigue habiendo una escisión entre el sistema turístico y el sector cultural, no existiendo en la práctica una fusión completa entre ambos, que ayude a que el turismo cultural se valore como un segmento unificado.

Como se destaca, el turismo cultural como actividad turística nació unida al patrimonio hace ya varias décadas. Se extendió entonces como una forma elitista de turismo, pero que evolucionó y se extendió rápidamente en el marco de los muchos cambios socioeconómicos vividos en España, país pionero e inspirador para el resto de Iberoamérica en la valorización turística sostenible del patrimonio cultural y natural. Este crecimiento- afirman los autores de la investigación- se acompañó de la proliferación de una oferta no excesivamente bien gestionada, mientras que desde el punto de vista de la demanda, ésta se dinamizaba y complejizaba.

El estudio "Turismo cultural: patrimonio, museos y empleabilidad" arroja luz sobre esta complejidad y refuerza la identidad del turismo cultural como categoría turística. Lo hace -como ya se ha manifestado- a partir de dos ejes de análisis: el de los atractivos turísticos patrimoniales corporizados a través de los museos y el potencial de empleabilidad, que no se puede escindir de la formación profesional y la cualificación que demanda. En tiempos de cambios vertiginosos, de nuevas tendencias y cambios de paradigma, es importante entender las perspectivas de empleabilidad que se ofrecen a los especialistas en la confluencia de dos tradiciones formativas: la del turismo y la de la cultura, aún con sus asperezas y dificultades, pero también con los esfuerzos que se están haciendo para su integración.

Este estudio pone en el centro del debate un tema abierto: el de las demandas y motivaciones que genera un turismo cultural cada vez más motivador.

Carmen María Ramos de Balcarce

Cátedra UNESCO de Turismo Cultural Untref/Aamnba

Buenos Aires carmenmariaramos@turismoculturalun.org.ar Recibida: 2-10-2013 Aceptada: 5-11-2013 